\title{
Como plantar um boneco no coração de alguém? - Desafios para o ensino do teatro de animação na Universidade
} How to seed a puppet in someone's heart? - Challenges of teaching puppetry techniques at the University

Miguel Vellinho ${ }^{2}$ 


\section{Resumo}

O autor apresenta os dois pilares de sua prática pedagógica. $\bigcirc$ primeiro é $\mathrm{O}$ método de trabalho que desenvolveu como diretor, ator e manipulador - para treinar profissionais na prática do Teatro de Animação. Seus procedimentos, aperfeiçoados nos 18 anos de sua companhia, aproximam o Teatro de Animação de outras linguagens. $O$ segundo pilar é seu trabalho como professor universitário, tendo criado a disciplina Teatro de Formas Animadas na UNIRIO, considerando os desafios do ensino público na Universidade - campo de formação profissional - e nos ensinos Fundamental e Médio - campos de trabalho dos futuros professores. Sua técnica busca vínculos entre artista e objeto animado, cuja expressão cênica é compreendida em sua totalidade desde a confecção dos bonecos, metodologia equivalente a uma gestação.

Palavras-chave: Teatro de animação; teatro de formas animadas; pedagogia teatral

\section{Abstract}

The author presents the two arms of his pedagogical practice. The first one is the work method Vellinho has developed - as a director, puppeteer and actor - to train professionals to the practice of the Animation Theater. His technical procedures have been improved throughout the 18 years of his company, by means of experimentations that approach the Animation Theater to other languages, as Cinema, Dance and Cartoon. The second arm is Vellinho's work since 2008 as a professor at the university. The director was responsible for the creation of the Animation Theater discipline at UNIRIO, considering the challenges of public education's reality in Brazil, both at University - field for the students' professional qualification - and at Elementary, Middle and High School - the largest work field for the future teachers. His work seeks to establish real and strong links between the artist and the animated object. In this process, the crafting of the puppets is a special highlight, because that is where begins the comprehension of the puppet in its scenic expression's entirety, a methodology Vellinho considers as a gestation.

Keywords: Animation theater; puppetry; theater pedagogy 
Minha experiência como docente formador em Teatro de Animação se iniciou nos anos 1990, quando comecei a ministrar algumas oficinas e cursos livres referentes ao tema que tinham o intuito de introduzir algumas premissas básicas do gênero, esboçando algumas regras fundamentais que poderiam servir de eixo para qualquer técnica - ou para a sua grande maioria. Tais regras refletem questões que eu julgava - e ainda julgo - serem essenciais para o bom manuseio de um boneco, ainda que eu acredite que o sentido maior da Animação não se restringe somente à absorção técnica. De nada serve a compreensão do foco do olhar do boneco, do eixo que garante seu equilíbrio, do nível que se relaciona diretamente com a permanência de uma mesma altura sempre e do ponto fixo que visa a sua estabilidade se o jogo interpretativo não estiver coadunado a estes princípios. Dificilmente seríamos convencidos de que algo inorgânico passou para uma outra condição, com alguma estranha forma de vida. Ou nem tão estranha assim. Ao longo do tempo, eu fui burilando alguns procedimentos de treinamento que extraíam dos discentes os melhores caminhos para o entendimento do que é Animação. E o que é o Teatro que considera esta Animação. Como foi dito acima, tais oficinas foram ministradas para interessados com maior ou menor grau de curiosidade na linguagem e artistas jovens que buscavam experimentar um novo tipo de expressão cênica. É importante salientar que, no Brasil, grande parte dos artistas que optam pelo Teatro de Animação são provenientes de oficinas e cursos livres, visto que não há formação profissional no âmbito das universidades brasileiras. E ainda é preciso falar do abismo cultural existente no país que concentra maior parte da produção cultural no Sudeste, onde se encontram as cidades de São Paulo e Rio de Janeiro.

Há, portanto, nesses encontros, o interesse, o fascínio e a curiosidade postos à disposição para serem conduzidos aos rudimentos deste segmento das Artes Cênicas.

A partir de tantas oficinas, cheguei a um momento em que necessitei formar novos profissionais para criar um espetáculo em que eu exerceria, pela primeira vez, a direção geral. Ou seja, eu digo que já me via com segurança para uma condução em médio prazo, com o intuito de assumir a liderança de um grupo relativamente fixo de pessoas. Assim, reunido com uma equipe bastante seleta de profissionais ligados ao Teatro - na maioria, atores -, esmiucei durante seis meses todo o meu processo docente realizado até então e tratei - neste caso, particularmente - de estudar e replicar a movimentação humana, visto que a técnica usada para o espetáculo em processo seria a manipulação direta. Por todo esse período, nós tratamos de segmentar os movimentos e criar uma adaptação compatível com a movimentação possível de executar com os bonecos criados para a montagem. Afora isso, havia, paralelamente à sala de ensaio, estudos sobre procedimentos usados por Muybridge ${ }^{2}$ para decupar as etapas da movimentação humana. Nessa fase do processo, percebi a potência de procedimentos usados nas oficinas que, com minúcia e muito mais horas de ensaio, propiciaram ao grupo uma verdadeira imersão no universo do Teatro de Animação, que também se completava com a criação e a confecção dos personagens usados no espetáculo. Percebi, portanto, que aquele momento, raro pela natureza das pessoas envolvidas e longo o bastante para se diferenciar das estritas horas das

\footnotetext{
Eadweard J. Muybridge (1830 - 1904), fotógrafo inglês conhecido por seus experimentos com o uso de múltiplas câmeras para captar o movimento humano e animal. Inventor do zoopraxiscópio, um dispositivo para projetar os retratos de movimento que seria o precursor da película de celuloide, que se popularizou ao longo do século XX com o advento do Cinema.
} 
oficinas ministradas, foi definitivo para minha formação como docente e encenador - e também para o elenco, que, a meu ver, saía de uma região de expressão artística restrita e ampliava potencialmente suas capacidades interpretativas. Faço minhas as palavras da professora Marthe Adam, quando nos aponta que:

Atuar com o boneco dá condições para desenvolver as faculdades do desdobramento, torna visivel o distanciamento, exercita a concentração, a exatidão do olhar e os vários niveis de presença" (Adam, 2015, p. 154).

Aqueles longos meses de preparação do meu primeiro espetáculo fomentaram a ideia de permanecermos juntos e trilhar uma mesma trajetória, reiterando o Teatro de Animação como característica principal da minha companhia, a PeQuod, que este ano chega aos seus dezoito anos de existência, com uma trajetória singular no Brasil.

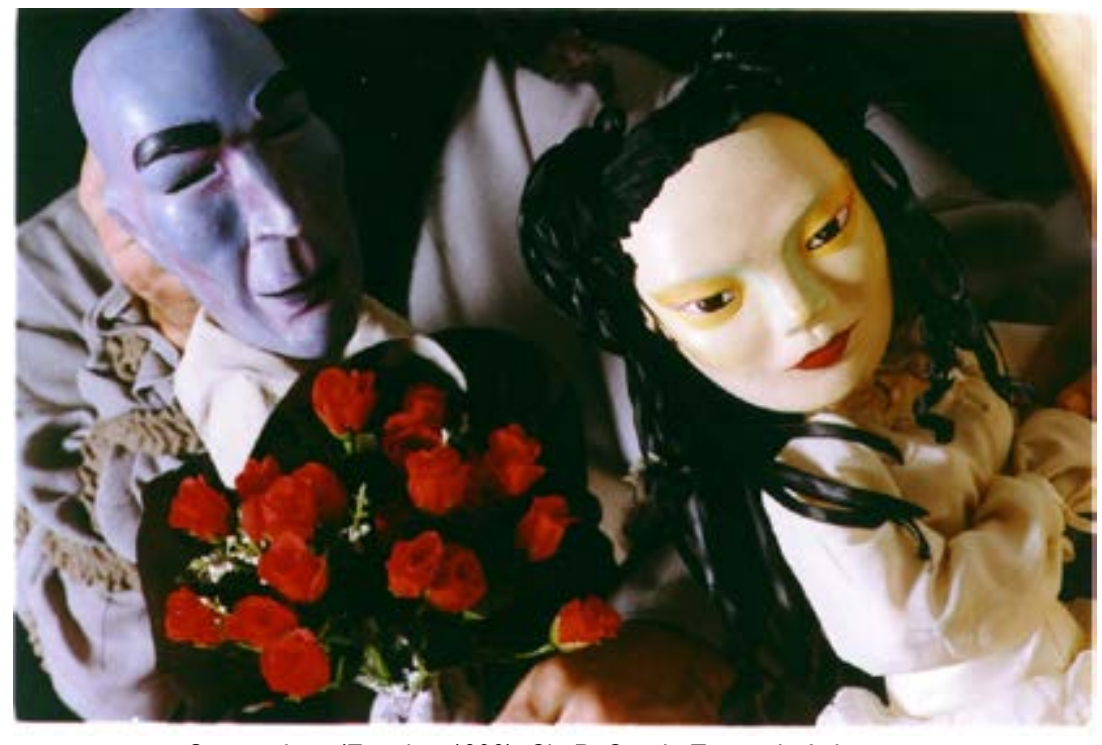

Sangue bom (Estreia - 1999). Cia PeQuod - Teatro de Animação. Diretor: Miguel Vellinho. Foto: Simone Rodrigues

Com mais de uma dezena de montagens que intercalam pesquisa e experimentação, a companhia acolheu, durante todo este tempo, vários profissionais que, em "safras" diferentes, aprenderam os procedimentos de manipulação por um desejo e por uma opção profissional que permite adentrar o mercado altamente ingrato das Artes Cênicas no meu país, tendo uma trajetória digna aliada a uma companhia que conquistou credibilidade e respeito ao longo do tempo. Neste período, por preferências pessoais e por afinidade técnica, optou-se pelo uso da manipulação direta como eixo das nossas encenações, visto que eu já tinha familiaridade com tal técnica e sabia transmitir, com certa eficiência, procedimentos de manuseio que eram satisfatórios. Destaco as particularidades dessa técnica eleita por sua aproximação com a movimentação humana, pela sua organicidade que induz o público a pensar estar diante de algo vivo, ainda que os seus manipuladores, no meu caso, estejam sempre à vista, e pela possibilidade de trançar o crível e o incrivel aos olhos da audiência em sequências de ações que, muitas vezes, são vertiginosas.

Tais elementos de sedução forjaram a primeira leva de manipuladores da PeQuod e, reiteradamente, ao longo da vida da companhia, são salientados em crí- 
ticas teatrais como um trabalho de excelência. Mesmo com uma certa fixação pelo uso contínuo de uma mesma técnica de manipulação, existem, a meu ver, diferenças imensas entre uma montagem e outra da PeQuod, na natureza de cada boneco, seja pela proporção usada - que difere a cada espetáculo -, seja por necessidades da própria configuração do personagem representado. De uma forma ou de outra, não há qualquer possibilidade de conforto ou tranquilidade nas escolhas feitas.

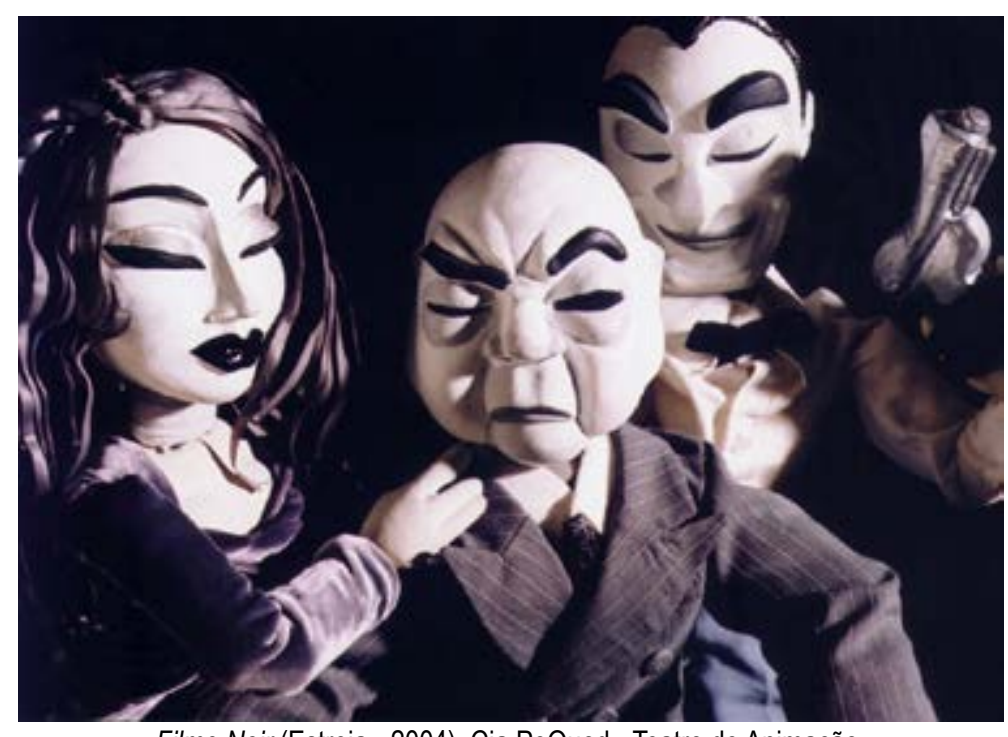

Filme Noir (Estreia - 2004). Cia PeQuod - Teatro de Animação.

Diretor: Miguel Vellinho. Foto: Simone Rodrigues

Num primeiro momento, calcamos nosso trabalho inteiramente no boneco antropomórfico como centro das encenações, porém, revirando alguns dogmas que nos levaram a aproximar nossas encenações da linguagem cinematográfica. $E$ nesse acercamento pode-se reconhecer uma das principais características iniciais da PeQuod. Os espetáculos, cada vez mais intrincados, propiciaram a verticalização de uma pesquisa iniciada em 1999 e que nunca cessou, inspirada, sobretudo, nos escritos de Eisenstein ${ }^{3}$. Procedimentos que unem a movimentação das mesas de manipulação durante a cena - sugerindo travellings - , duplicação dos bonecos - para a facilitação de seu deslocamento pelo palco - e um tipo de uso da iluminação cênica - que "editava" as cenas - foram as bases de nossa interlocução com a gramática do cinema narrativo, que serviu de mote para algumas das nossas principais e mais celebradas encenações, como Sangue Bom (1999), uma história de vampiro; Filme Noir (2004), espetáculo em preto e branco que emulava o subgênero cinematográfico no palco; e Marina (2010), adaptação musical e subaquática do conto A Sereiazinha, de Hans Christian Andersen.

\footnotetext{
${ }^{3}$ Sergei Mikhailovitch Eisenstein (1898 - 1948), um dos mais importantes cineastas soviéticos, ligado ao movimento de arte de vanguarda russa, participou ativamente da Revolução de 1917 e da consolidação do Cinema como meio de expressão artística. Seus filmes mudos, como A Greve (1924), O Encouraçado Potemkin (1925), Outubro (1927), Alexandre Nevski (1938) e Ivan, o Terrível (1944) são conhecidos, respeitados e estudados mundialmente. Suas obras em livro A Forma do Filme (1929) e O Sentido do Filme (1942) trouxeram contribuições definitivas sobre o uso da montagem cinematográfica e influenciam o cinema clássico narrativo até hoje.
} 


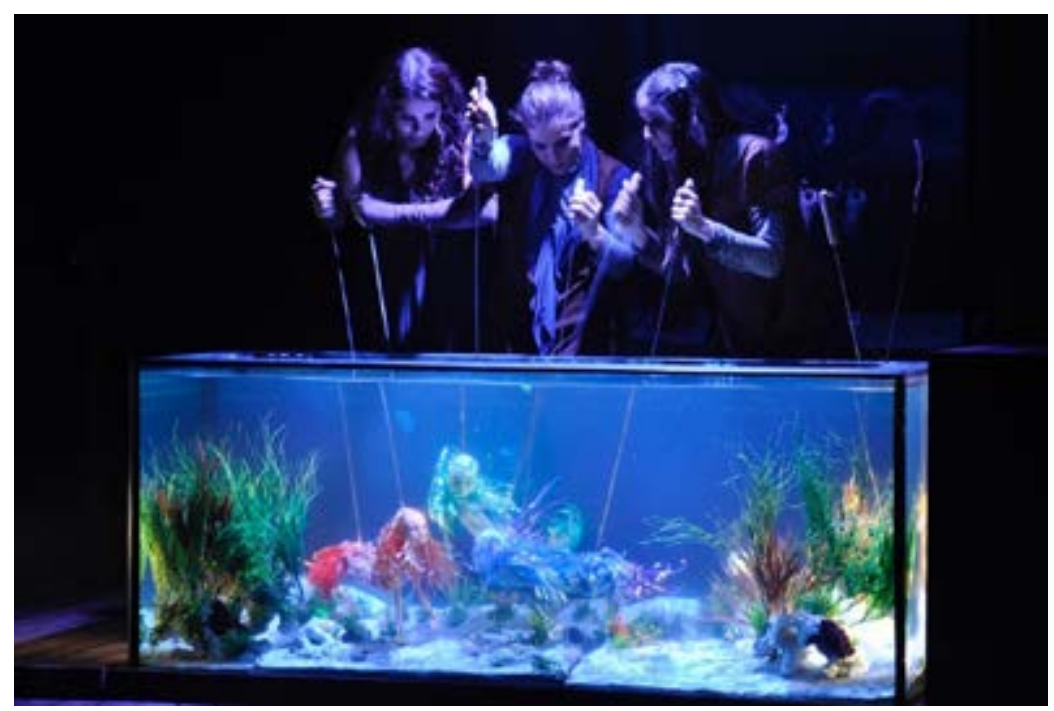

Diretor: Miguel Vellinho. Foto: Simone Rodrigues

Houve, nesta trajetória, dois outros momentos que se destacam pela sua importância como deflagrador de uma nova investigação interna que propiciou novos desdobramentos, seja na forma espetacular, seja na reflexão acadêmica e textual, e que realinhou a minha percepção pedagógica frente ao grupo de atores que eu tinha comigo. Em Peer Gynt ${ }^{4}$ (2006), nossa montagem que marcou o centenário de morte de Henrik Ibsen no Brasil, partimos para uma cena híbrida que permitia, respondendo a um apelo do elenco na época, que atores e bonecos estivessem em mesmo pé de igualdade em cena. Partindo de uma premissa que se relacionava com a dúbia condição moral do protagonista, a cena ora abarcava e apresentava Peer com a figura de um ator, ora como um personagem na forma de um boneco. E outras duplicidades replicavam este procedimento, para uma melhor resolução cênica, que prescindia ou não de bonecos. Também em Peer Gynt, apareceram os primeiros bonecos afastados de uma configuração antropomorfa, como o caso da personagem Curva, que se resumia a uma fita de ginástica artística que era acionada por um ator que após ser içado pelo elenco e passar a assumir o estado do personagem de cabeça para baixo e a cerca de três metros acima do chão, dialogava com o protagonista, através de impulsos criados a partir da movimentação da fita, que o levava até um duelo. Esta nova forma de composição física de um personagem neste momento do espetáculo, instaurava novas camadas de discussão sobre aspectos não figurativos sugeridos pelo próprio autor norueguês.

O aspecto híbrido de nossa montagem de Peer Gynt abriu caminho para outras encenações que buscavam outras possibilidades de uso. Foi o caso da hibridação segmentada vista em $A$ Chegada de Lampião no Inferno 5 (2008), espetáculo cujos vinte minutos finais contavam exclusivamente com atores, sem os bonecos, por motivos absolutamente ligados à dramaturgia ${ }^{6}$. É um caso diferente do hibridismo por sobreposição visto na versão adulta do espetáculo Marina ${ }^{7}$ (2010), em que as cenas se sobrepunham com atores e bonecos atuando em diferentes níveis do espaço cênico

\footnotetext{
${ }^{4}$ Estreado em 31 de agosto de 2006 no Teatro de Arena do Espaço SESC, no Rio de Janeiro (RJ) com o seguinte elenco: Liliane Xavier, Mário Piragibe, Maria Cristina Paiva, Márcio Nascimento, Márcio Newlands e Mona Vilardo.

${ }^{5}$ Estreado em 15 de abril de 2009 no Teatro III, do Centro Cultural Banco do Brasil (CCBB), no Rio de Janeiro (RJ), com o seguinte elenco Gustavo Barros, Liliane Xavier, Marise Nogueira, Marcio Nascimento e Thiago Picchi
} 
simultaneamente. Tais misturas deram novo impulso ao trabalho iniciado em Peer Gynt, além de ter atraído uma nova leva de artistas para a companhia, que, por tudo que foi dito aqui, acabaram por ter pouco contato com o boneco antropomorfo e, portanto, pouca experiência com a manipulação direta.

Não quero parecer cabotino ao expor aqui apenas os momentos positivos de nossa trajetória - destaco, com orgulho, a grande crise interna que acompanhou o processo de montagem de $A$ Tempestade ${ }^{8}$ (2012), de Shakespeare, e que resultou na expulsão dos bonecos de cena. Não exatamente da sua totalidade, visto que havia, perpassando toda a trama, sutis experimentações com o Teatro de Sombras, de uma forma até bastante heterodoxa. No entanto, a desmesura existente entre o grupo de profissionais reunidos expôs, infelizmente, visíveis deficiências de atuação que geraram um espetáculo distanciado em muito dos propósitos iniciais ou principais da companhia. Nossa versão de $A$ Tempestade entrou no rol de outras tantas experiências contemporâneas com a obra shakespeariana sem muitas contribuições efetivas, e a ausência do objeto animado equiparou a PeQuod a outras tantas companhias de atores existentes na cidade do Rio de Janeiro, um dos principais polos de produção teatral do Brasil, sem nenhum brilho ou mesmo destaque especial. No entanto, a urgência por uma recuperação da principal característica da companhia fez com que embarcássemos em um dos mais profundos e coerentes processos de trabalho já vividos pelo grupo e que tinham por norte a recuperação da figura do boneco, desta vez, através da Dança. Ou melhor dizendo, através do gesto poético e não cotidiano.

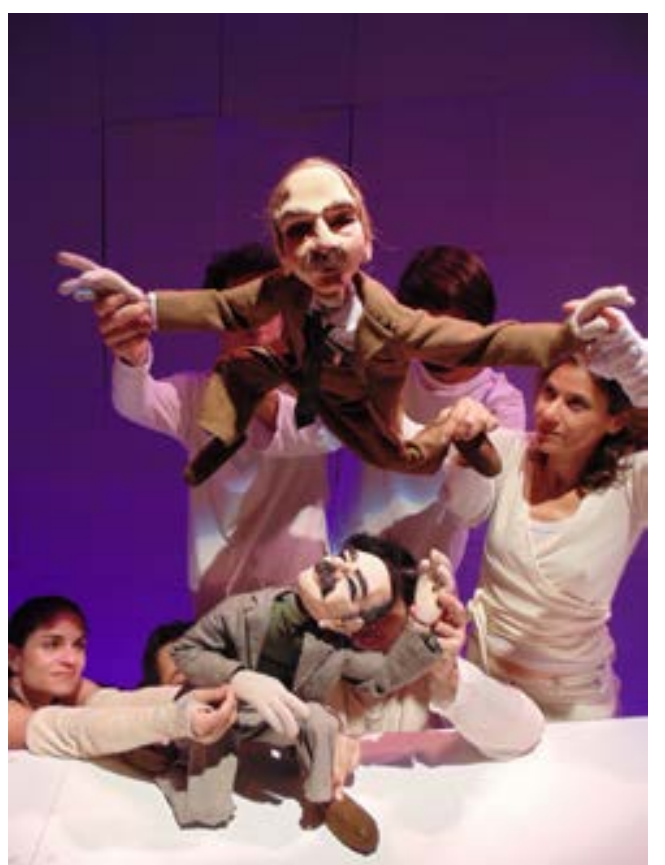

PEH QUO DEUX (Estreia - 2014). Cia PeQuod - Teatro de Animação. Diretor: Miguel Vellinho. Foto: José Roberto Crivano

\footnotetext{
${ }^{6}$ A Chegada de Lampião no Inferno é uma montagem que nasceu da tradição popular da literatura de cordel do nordeste brasileiro, mesclada aos procedimentos de artesanato em cerâmica da mesma região do país. Utilizando-se da metáfora dos processos de finalização desse tipo de artesanato, a cena recria 0 ambiente de produção dessas peças, desde a limpeza da argila, passando pela moldagem, queima das peças em forno e finalização com a pintura. A metáfora utilizada aproxima a vida de Lampião, um dos mais famosos cangaceiros nordestinos do início do século XX, dessa manifestação cultural, tendo a ida ao forno replicada como se fosse uma descida ao inferno, recriando com cores locais a trajetória de Dante Alighieri, na obra A Divina Comédia.

${ }^{7}$ Estreado em 06 de agosto de 2010 no Teatro III do Centro Cultural Banco do Brasil (CCBB), no Rio de Janeiro (RJ), com o seguinte elenco Liliane Xavier, Mariana Fausto, Mona Vilardo, Leandro Muniz, Marcio Nascimento e Miguel Araújo.

${ }_{8}^{8}$ Estreado em 26 de outubro de 2012 no Teatro do Jockey, no Rio de Janeiro (RJ), constavam no elenco: André Gracindo, Gustavo Barros, Liliane Xavier, Raquel Botafogo, Mariana Fausto, Miguel Araújo, Paulo Giannini, Thales Coutinho e Pedro Florim
} 
O espetáculo PEH QUO DEUX9 (2014) - cujo nome é um trocadilho entre o nome da companhia e pas de deux ${ }^{10}$ - é, a meu ver, a terceira e mais recente revirada estética nascida dentro da PeQuod, dada a singularidade de seu conceito: cinco renomados coreógrafos de Dança, com trajetórias temporais distintas, foram convidados a criar cinco quadros coreográficos, cinco pas de deux que tinham por norte pensar em um trabalho que nenhum bailarino humano conseguisse dançar, só possível de ser executado por um boneco. Tive a felicidade de acompanhar e orientar cinco grandes nomes da Dança Contemporânea brasileira e reaprender a olhar a figura antropomorfa, de uma nova maneira, sem a presença da gestualidade cotidiana e/ou causal. Isso foi uma lufada de renovação que interferiu no meu - no nosso - modo de olhar, de ensaiar, de manipular e de confeccionar bonecos. Digo tudo isso para demonstrar o quanto é importante, na condução de uma companhia, a escuta interna - que molda minhas necessidades de experimentação - e também uma escuta externa - que abarca os anseios dos integrantes, bem como do público, que se tornou fiel ao longo dos anos. A harmonia dessas escutas, desvencilhadas de preconceitos, de juízos e certezas absolutas, tem feito da PeQuod um espaço de atividade experimental no Teatro de Formas Animadas, que nos permite desenhar a nossa trajetória com verticalidade e coerência. Assim também meus procedimentos pedagógicos se sofisticaram, se alinharam a novas formas de percepção da figura animada, que me fazem avançar por caminhos surpreendentes, na maioria das vezes. A aproximação com a Dança, a meu ver, é uma trilha nova com muitas verificações pela frente, que me estimula a adensar mais a pesquisa existente já esboçada e permite entrar na sala de ensaio de forma renovada. Rejuvenescida, melhor dizendo.

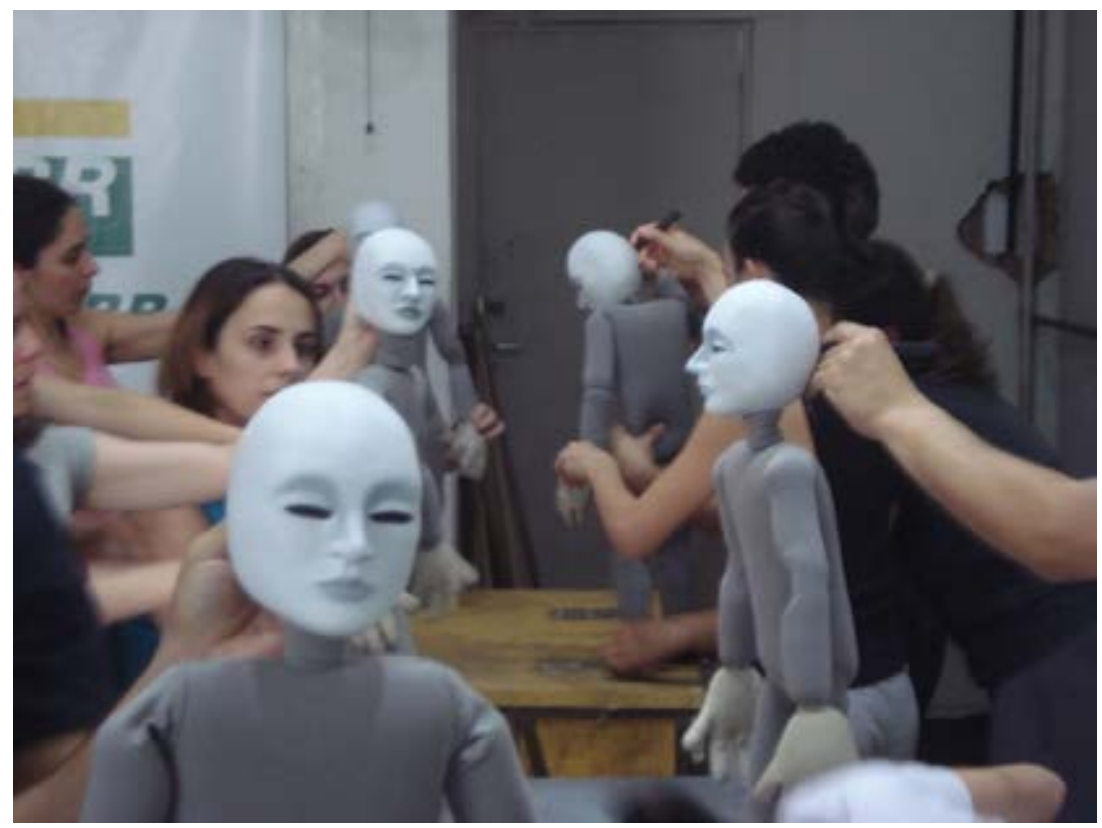

Foto de oficina realizada na sede da companhia (2011). Cia PeQuod Teatro de Animação. Diretor: Miguel Vellinho. Foto: Miguel Vellinho

\footnotetext{
${ }^{9}$ Estreado em 09 de janeiro de 2014 no Teatro do Oi Futuro Flamengo, No Rio de Janeiro (RJ) com o seguinte elenco: Liliane Xavier, Mariana Fausto, Raquel Botafogo, André Gracindo, Marcio Newlands e Miguel Araújo.

${ }_{10}$ Termo técnico vindo do balé clássico e que denomina um dueto, geralmente dançado por um homem e uma mulher que executam juntos uma coreografia.
} 
Tudo acima foi dito tendo em mente a propagação de conhecimentos acerca do trabalho com formas animadas, a partir de uma perspectiva que envolve interesses profissionais comuns. Quando entrei na Universidade Federal do Estado do Rio de Janeiro (UNIRIO), há quase dez anos, para compor o quadro de professores do novo curso de Licenciatura em Teatro ${ }^{11}$, que contava com a novidade de oferecer as disciplinas de Teatro de Formas Animadas e Teatro Infanto-juvenil em seu currículo, entendi que era preciso uma verificação profunda dos meus procedimentos de docência, que ali deveriam dialogar com a realidade do ensino público brasileiro e, assim, criar novas estratégias de contaminação da linguagem da animação entre os alunos que necessariamente deveriam passar pela minha disciplina, visto que ela é obrigatória para a sua graduação. Teatro de Formas Animadas é uma disciplina de oito horas semanais, sem qualquer relação com as outras disciplinas do curso, que recebe, sobretudo, jovens entre 20 e 30 anos que chegam, infelizmente, com uma ideia bastante vaga do que venha a ser esse gênero. Chegam, muitas vezes, com o olhar displicente do jovem adulto que vê o Teatro de Animação como uma reminiscência da infância, um universo recém-abandonado e que, por ora, não parece interessante de ser revisitado. Outros chegam, vindos do interior do país, com pouca ou quase nenhuma informação ou memória do que se trata o Teatro de Formas Animadas e, graças a projetos de mobilidade acadêmica, conseguem transferência para uma cidade com maior produção cultural, como é o caso do Rio de Janeiro. Uns chegam com maior boa vontade de tentar absorver algo que lhes é imposto; outros, nem tanto.

Diante deste quadro, logo quando iniciei as disciplinas, eu me vi com as mesmas indagações de Lorefice quando diz: "Seria possivel ensinar? Ensinar o quê? É possível transmitir conhecimentos, técnicas de base, procedimentos criativos, mas... isso basta?" (Lorefice, 2015, p. 80). Como é possivel plantar um boneco no coração de alguém? E em tão pouco tempo! Por tão poucos meses! Por tão ínfimas horas! Está claro que a função da disciplina na grade curricular é abrir o leque de possibilidades pedagógicas de que o futuro professor pode se utilizar na sua vida profissional. Ela está ali demarcando um avanço, mas é uma coadjuvante nesse processo de formação do futuro professor. No entanto, por acreditar que a disciplina pode estabelecer vínculos muito mais profundos dentro ou fora da sala de aula, fui em busca de algo que criasse uma conexão, se possivel, definitiva entre os alunos e seus respectivos objetos animados. A realidade, porém, me dá trinta aulas de duas horas por semestre para realizar tal plantio.

Na minha formação, que começa com alguns mestres brasileiros e passa por Phillipe Genty, entendi que a confecção dos bonecos não é apenas uma etapa importante a ser trabalhada e dominada, mas também algo fundamental para uma construção íntima do artista que trabalha com formas animadas. Ao lidar com os materiais que irão compor o futuro objeto animado, ganha-se desembaraço no uso de inúmeros elementos que envolvem as etapas da confecção, aprende-se a boa utilização dos produtos, entende-se a natureza de cada material envolvido, cria-se uma

\footnotetext{
11 O curso de Licenciatura em Teatro, hoje ligado a um departamento próprio, o Departamento de Ensino de Teatro, que é parte da Escola de Teatro da UNIRIO, acolhe alunos para a formação de professores de Teatro que, em grande parte, são absorvidos pelo ensino público fundamental e médio. Com a duração de quatro anos e com uma grade que abarca disciplinas do curso de Teoria Teatral, de Atuação Cênica, de Cenografia e de Pedagogia, além das do próprio curso, a Licenciatura em Teatro rapidamente atingiu um grau máximo 5 de pontuação do Ministério da Educação na sua primeira avaliação com a nova versão curricular.
} 
rede de conhecimentos que podem gerar substituições criativas e surpreendentes no futuro. É nesse momento, com a forma final do boneco ainda distante dos olhos, é que se faz, ou começa a nascer, a verdadeira ideia do que é um boneco e qual é a sua função. Todo esse processo ainda poderia ser mais ameno, se estivéssemos num ambiente que acolhesse bem os alunos, se as condições espaciais e de acomodação fossem as melhores possíveis e se houvesse acesso irrestrito aos melhores materiais para a confecção dos bonecos. No entanto, volto a lembrar da dura realidade do ensino público no Brasil, que nos leva a ser mais criativos do que podemos imaginar ser, para driblar as imensas limitações de verba. Assim, diante de tal quadro, eu obviamente abro mão da utilização de materiais caros, comumente usados nos processos de confecção dos bonecos nos meus espetáculos, e, longe do que pode parecer uma improvisação, o trabalho de construção dos bonecos se fundamenta na utilização de materiais de fácil acessibilidade e que não exigem, inicialmente, muitas habilidades dos alunos.

Digo isto porque é nesse momento que bloqueios de manuseio do material costumam aparecer. É preciso ter uma delicadeza para fazer os alunos superarem a inabilidade manual que muitas vezes aparece nesse momento. Obviamente, eu não começo a disciplina de forma rígida ou tecnicista demais. Pelo contrário, a entrada dos alunos nesse universo se dá com um módulo intitulado Estudo das Formas, que tem por objetivo perpassar pela observação e análise das formas em 2D e sua transposição para a terceira dimensão. Ao sair da figura plana, o aluno é levado a reconhecer o significado do volume e qual é a sua função na composição da figura e, por fim, descobrir as melhores resoluções para definir visualmente alguma coisa. Nesse momento, experimenta-se alguns processos de confecção, sem ainda o compromisso de chegar a uma figura finalizada. São tais experimentos que proporcionarão, mais tarde, uma maior desinibição no manuseio e utilização dos materiais. Por fim, com tais experimentos finalizados, chega-se ao primeiro momento de deslocamento expressivo do curso, ao trabalharmos com a sombra criada pelo objeto. Com a dissipação do material concreto, os alunos passam a conhecer a beleza misteriosa de sua imaterialidade e suas infinitas possibilidades cênicas.

Passada a etapa citada acima, apresento-lhes, então, um grande apanhado de imagens coletadas ao longo de muitos anos, retiradas de livros, programas de espetáculos e enciclopédias diversas, que permitem adentrar nas esferas visuais, técnicas, históricas e geográficas do Teatro de Animação, obviamente apresentando as principais técnicas de manipulação, que precisam entrar no vocabulário, e as inovações que surgem na contemporaneidade que ampliam a visão antropomórfica e/ou zoomórfica que se costuma dar ao boneco. É claro que este recorte, por mais amplo que seja, não abarca todas as manifestações, o que seria impossível; no entanto, a profusão de imagens dadas propicia uma boa gama de resoluções que podem ser usadas pelos alunos em seus próprios projetos.

Como disse acima, portanto, o cerne do curso acontece quando o grupo de alunos começa a preparar seu projeto do boneco a ser confeccionado em aula. Nesta proposta, a ideia é que os alunos pratiquem as técnicas de confecção trabalhadas anteriormente para a criação de um boneco de luva. Penso que o boneco de luva, uma técnica clássica, é a melhor opção para um exercício inicial nesse universo, até 
pelo tempo exíguo que temos. Como aponta Balardim, a escolha desta técnica se dá também graças a

[...] sua ampla difusão no contexto brasileiro [...] e por acreditar que essa técnica pode possibilitar ao ator experimentar as bases da manipulação que irão compor a poética dos bonecos, uma vez que [...] é possível manter o olhar do manipulador direcionado para o boneco, podendo ter uma boa apreensão de toda a sua forma e movimentação espacial. (Balardim, 2009, p. 159)

Enfim, penso que existem outras maneiras de se entranhar nesse mundo, mas percebo que a luva, por sua forma sintética e ao mesmo tempo tão complexa, dá ao iniciante uma resposta rápida do quão rica pode ser esta manifestação.

Respeitando todas as individualidades e particularidades, costumo deixar o aluno livre para escolher o personagem a ser confeccionado, excetuando-se as figuras egressas da indústria cultural de massa, que, no processo, penso eu, nos desviariam de uma construção simbólica que corre silenciosamente e paralelamente às aulas. Com as escolhas feitas, os alunos têm um dia de aula para apresentar seus projetos visualmente, seja com desenhos próprios, seja na união de material referencial que, organizado de forma clara, permite-nos um entendimento da figura final. A importância do projeto é a primeira instância de mantê-los firmes num mesmo propósito até a finalização. Não faço com isto inviabilizar os desvios, que também acredito existirem a todo momento e são absolutamente válidos e tentadores; porém, a ideia de um projeto que pode possuir instâncias abertas deixa clara a consciência de um objetivo terminal. É uma demarcação decidida pelo próprio aluno, mas também um acordo que fazemos juntos. Ao longo de algumas semanas, o processo de confecção se verticaliza, exigindo de cada aluno decisões, escolhas e entendimento de um processo muito particular que chamo de gestação do boneco. Nesse movimento análogo a uma gravidez, tem-se a percepção clara do momento em que tais exigências materiais que vão entrando no processo de confecção deixam de ser um fardo, uma obrigação, e se tornam algo absolutamente excitante e que catapultam o desejo dos alunos em verem o objeto pronto. Esta inversão, que contagia a todos em sala de aula, não se dá apenas por liberarem-se de uma etapa arrastada da disciplina, mas por começarem a ver naquela junção de "papel, tinta, madeira e tecido" algo absolutamente seu, criado por eles e absolutamente único. Este enamoramento me preocupava quando comecei a dar aulas, visto que também é preciso olhar o boneco novamente com desprendimento, como um artefato cênico, como um adereço, como algo que só atinge a sua completude no palco, na cena. O encantamento, por vezes, pode atrapalhar a finalização deste processo e, frequentemente, desajustar um processo que acontece também coletivamente.

Há claramente um deslocamento de libido nesse processo de gestação, ao qual há que se ter atenção e cautela, pois muitas das criações que surgem em sala de aula mexem com projeções e transferências dos alunos e necessitam de um amparo muito mais que técnico. Nenhuma escolha é absolutamente aleatória e, evidentemente, há um jogo de identificação e subjetividade bastante evidenciado nesse processo. Não é à toa o surgimento de tantos orixás ${ }^{12}$, tantos personagens fantásticos e tantas celebridades do mundo da música, do cinema e da televisão que povoam o universo íntimo 
e referencial de cada aluno, que encontram na disciplina um canal de reconexão com tais figuras e com seu próprio imaginário. Nesse momento, meu olhar precisa estar atento para aquela ideia materializada que ainda necessita de ajuste e de complementações, que tanto podem ser com acréscimos materiais, ou com substituições, como também dando maior ênfase ao que está, por vezes, timidamente esboçado. Refaço aqui a ideia do boneco de luva como uma replicação sintética do homem; portanto, tudo nele pede condensação e concentração. Minha tarefa nesse momento é a de potencializar as propostas. Dar uma finalização em acordo ao personagem criado, sugerir materiais diversos e mais adequados para uma melhor resolução visual, salientar características do mesmo com maiores estímulos visuais - muitas vezes, isto passa por composição de cor, apresentação e uso de materiais rotineiros e não rotineiros que podem contribuir para uma melhor apresentação do boneco. É sempre bom lembrar que há materiais que, apesar de sua popularidade entre os bonequeiros em geral, estão distantes da vida de um universitário. A apresentação de tais elementos aprofunda o entendimento da larga variedade de materiais que pode entrar no jogo da confecção e demonstra que o não-convencional sempre será bem-vindo, visto que pode ser entendido como um disparador de uma nova informação dada ao boneco. Muitas vezes, podemos compreender a natureza de um personagem graças à escolha dos materiais envolvidos na sua confecção.

O final da confecção implica em novos desafios que estão nos exercícios que envolvem a prática da manipulação de luva, sua decorrente descoberta da vocalidade própria de cada boneco e suas mais diversas relações - com o próprio manipulador, com outro boneco, com o público. É um processo que, mesmo condensado, deságua em resultados grandiosos. Posso dizer que isso é gratificante para mim, que consegui instaurar uma relação nova e profunda entre animados e animadores e vejo também o mesmo sentimento entre os alunos que abandonaram a displicência inicial de encarar uma passagem obrigatória e inóspita do curso e encontraram na disciplina muito mais do que imaginavam encontrar. Enfim, se existe um grande desafio na docência superior, ele não está na carência de condições físicas, espaciais e materiais na universidade pública brasileira hoje. Obviamente, tudo seria extremamente mais sedutor se tais necessidades fossem um dia superadas, mas creio estarmos distantes disso. Transformar o olhar do aluno é, sim, a grande batalha a ser trabalhada semestralmente em minha disciplina, em tão curto tempo. Importa ter as ferramentas certas e as mãos firmes para abrir-lhes o peito e plantar com cuidado e apreço uma semente que lhes pode acompanhar pelo resto da vida. Pois, assim, um dia, aconteceu comigo.

Um parágrafo de orgulho antes de finalizar: Desde que comecei a lecionar na Universidade, pude encontrar em alguns alunos a mesma fagulha de encantamento que tive ao adentrar neste campo profissional e, pouco a pouco, promovi a entrada deles na minha companhia, possibilitando um contato maior e mais profícuo com a profissão. Três deles já estão na PeQuod há quase dez anos. Lentamente, a presença de universitários na sala de ensaio começou a deixar de ser uma exceção ao grupo que já estava comigo desde os primeiros anos da companhia e, aos poucos, essa transição da Universidade para a vida profissional real tem se repetido de forma cada vez mais

${ }^{12}$ Divindades das religiões afro-brasileiras. 
constante. Constato que essa é, verdadeiramente, uma porta que se abriu na companhia e que dificilmente irá se fechar. O mais interessante é ver essa transformação de aluno para colega de trabalho, do seu próprio trabalho, de alguém que entra no seu espaço da criação. Em maio deste ano - 2017 - , a PeQuod estreou mais um espetáculo e informo-lhes, com exaltação, que os ex-alunos são uma maioria no elenco.

\section{Referências}

ADAM. Marthe. Boneco e atuação de ator: uma reflexão. Móin-Móin - Revista de estudos sobre Teatro de Formas Animadas, ano 11 - número 14, Jaraguá do Sul, UDESC/ SCAR, 2015.

BALARDIM, Paulo. O fio transversal da animação. Móin-Móin - Revista de estudos sobre Teatro de Formas Animadas, ano 05 - número 06, Jaraguá do Sul, UDESC/ SCAR, 2009.

LOREFICE, Tito. Reflexões sobre a formação e o vínculo entre Professor e Aluno, Mestre e Aprendiz. Móin-Móin - Revista de estudos sobre Teatro de Formas Animadas, ano 11 - número 14, Jaraguá do Sul, UDESC/SCAR, 2015.

Este texto também se encontra publicado em inglês neste número do periódico.

Recebido em: 22/05/2018

Aprovado em: 22/05/2018 